ISSN: 1858-4837; E-ISSN: 2598-019X

Volume 16, Nomor 2 (2021),

https://jurnal.uns.ac.id/region

DOI: 10.20961/region.v16i2.39747

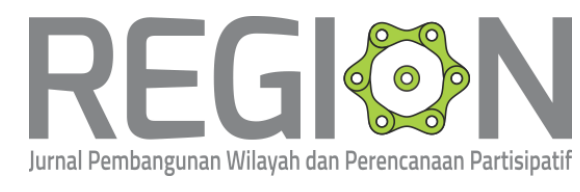

\title{
Karakteristik aktivitas dan lokasi PKL di Jalan Badak V
}

\author{
The characteristics of street vendor activities and locations on Jalan Badak V \\ Semarang
}

\author{
R R W Lestari ${ }^{1}$, A B Sardjono ${ }^{1}$, dan S R Sari ${ }^{1}$ \\ ${ }^{1}$ Master of Architecture Department, Diponegoro University, Semarang, Indonesia
}

Corresponding author's email: riaripardi@gmail.com

\begin{abstract}
Abstrak. Penelitian ini didasari oleh pedagang kaki lima yang menggunakan jalan Perumahan Badak $V$ sebagai aktivitas berdagang mulai pagi hari sampai malam hari. Adanya PKL pada jalan perumahan memiliki daya tarik tersendiri terhadap masyarakat sekitar karena memudahkan dalam memenuhi kebutuhan sehari-hari sehingga pada tempat dan waktu yang sama terjadi aktivitas yang bercampur dan saling mempengaruhi antara pedagang dan pengguna jalan. Tujuan dari penelitian ini adalah untuk mengkaji karakteristik pedagang kaki lima dari aktivitas dan lokasi yang dipilih dalam berdagang sehingga PKL dapat ditata dan jalan dapat digunakan sesuai fungsinya. Penelitian ini menggunakan metode deskriptif kualitatif. Hasil penelitian adalah karakteristik aktivitas PKL berbeda dan bervariasi di pagi hari, siang dan malam hari selain itu dipengaruhi oleh kegiatan di sekitar Jalan Badak V.
\end{abstract}

Kata Kunci: Jalan Perumahan Badak V; Karakteristik Aktivitas; Karakteristik Lokasi; Pedagang Kaki Lima

\begin{abstract}
This research is based on street vendors who use the Badak $V$ residential road as a trading area from morning to night. The existence of street vendors on residential road has a special attraction to the surrounding community because it makes it easy to fulfil the daily needs so that at the same place and time there is mixed activity and mutual influence between traders and road users. The purpose of this study is to examine the characteristics of street vendors based on the activities and their preference on choosing their trading location. Thus, street vendors can be arranged and the road can be used according to its function. This study used descriptive qualitative method. The results shows that the activity characteristics of
\end{abstract}


street vendors are different and varies in the morning, afternoon, and evening. In addition, the characteristics are also influenced by the activities around Jalan Badak V.

Keywords: Activity Characteristics; Location Characteristics; Street Vendors; Badak V Residential Road

\section{Pendahuluan}

Jalan perumahan adalah salah satu struktur penting dari suatu kota dalam suatu sistem jaringan jalan perkotaan. Peranan jalan ini jika berfungsi dengan baik dapat menentukan kualitas sebuah kota, serta memberikan kenyamanan dan kesejahteraan bagi warganya. Jalan perumahan yang baik harus dapat memberikan rasa aman dan nyaman bagi pergerakan pejalan kaki, pengendara sepeda dan pengendara kendaraan bermotor lainnya, seperti trotoar, drainase, lansekap, rambu lalu lintas, marka jalan, parkir, shelter dan lain lain [1]. Jalan perumahan merupakan salah satu struktur penting dari suatu kota dalam suatu sistem jaringan jalan perkotaan. Jika peran jalan perumahan dapat berfungsi dengan baik maka dapat menentukan kualitas sebuah kota. Jalan perumahan yang baik harus dapat memberikan rasa aman dan nyaman bagi pergerakan pejalan kaki, pengendara sepeda dan pengendara kendaraan bermotor lainnya, seperti trotoar, drainase, lansekap, rambu lalu lintas, marka jalan, parkir, shelter dan lain-lain. Dalam studi di Kanada dan Australia yang dilakukan oleh Gehl pada tahun 1980, mengidentifikasi enam aktifitas utama yang berlangsung pada jalan lingkungan permukiman, yaitu orang-orang duduk atau berdiri; orang melakukan aktifitas tertentu, seperti memperbaiki motor/mobil, perbaikan-perbaikan pada properti, dan sebagainya, berjalan, interaksi sosial, anak-anak bermain, dan pergerakan lalu lintas.

Jalan Badak $\mathrm{V}$ merupakan jalan perumahan yang dibuat dengan tujuan sebagai fasilitas prasarana penghuni perumahan dan jalur penghubung. Tetapi mulai tahun 2000-an muncul pedagang yang berjualan pada pagi hari dijalan utama (Jalan Kolektor/Lokal Sekunder). Pengertian Pedagang Kaki Lima menurut PERDA Kota Semarang Nomor 11 tahun 2000, pedagang kaki lima atau yang disingkat PKL adalah pedagang yang di dalam usahanya mempergunakan sarana atau perlengkapan yang mudah di bongkar pasang/dipindahkan dan atau mempergunakan tempat usaha yang menempati tanah yang bukan hak miliknya [2].

Setiap tahun jumlah pedagang semakin bertambah sehingga pada tempat dan waktu yang sama terjadi penambahan fungsi pada jalan perumahan yang bercampur dan saling mempengaruhi yaitu pedagang memanfaatkan jalan sebagai area komersial dan masyarakat sekitar memanfaatkannya sebagai jalur transportasi. Hal ini terjadi karena adanya interaksi antara pengguna sehingga memberikan peluang terjadinya aktivitas itu di tempat yang sama [3]. Keberadaan PKL di jalan perumahan memberikan dampak positif dan negatif bagi masyarakat dan lingkungan sekitar sehingga diperlukan penanganan dan perhatiaan khusus untuk para PKL. Dengan demikian, langkah awal yang diperlukan adalah mengindentifikasi dan menganalisis karakteristik lokasi dan aktivitas pedagang kaki lima. 


\section{Metode}

Tahapan penelitian ini terdiri dari beberapa tahap yang pertama adalah teknik pengumpulan dengan dokumentasi, wawancara dengan pedagang kaki lima di lokasi penelitian dan observasi langsung ke lapangan mengamati aktivitas pedagang kaki lima pada pagi hari jam 05.00-09.00, siang hari 12.00-16.00, dan malam hari 17.00-21.00. Tahap berikutnya dengan melakukan metode place centered mapping dan person centered mapping untuk menganalisa perilaku pedagang kaki lima dalam beraktivitas.

\section{Hasil penelitian dan pembahasan}



Gambar 1. Peta lokasi Jalan Badak V.

Jalan Badak V (Gambar 1) merupakan jalan perumahan dengan lebar \pm 5 meter dan termasuk Bagian Wilayah Kota (BWK) V, Kecamatan Gayamsari Kota Semarang. Sepanjang Jalan Badak $V$ terdapat perumahan Badak Perumahan Puri Bimasakti, SDN 2 Pandan Lamper, perkantoran, dan pertokoan. Kegiatan yang berlangsung pada Jalan Badak $V$ antara lain:

Kegiatan pendidikan

Kegiatan perkantoran

Kegiatan komersial

Kegiatan perumahan (24jam)

Kegiatan PKL

$$
\begin{aligned}
& \text { : jam } 06.00-16.00 \text { WIB } \\
& \text { : jam } 08.00-17.00 \text { WIB } \\
& \text { : jam } 07.00-21.00 \text { WIB } \\
& \text { : jam } 00.00-24.00 \text { WIB } \\
& \text { : jam } 05.00-21.00 \text { WIB }
\end{aligned}
$$

\subsection{Waktu aktivitas PKL}

3.1.1 Pagi hari (05.00 - 09.00 WIB). Aktivitas PKL pada pagi hari dimulai pada pukul 05.0009.00 WIB dengan menggunakan bahu dan badan Jalan Badak $V$ sebagai tempat berdagang dan parkir. Selain itu aktivitas PKL pagi hari bersamaan dengan jam kantor sehingga menimbulkan kemacetan pada simpul jalan (lihat Gambar 2). 


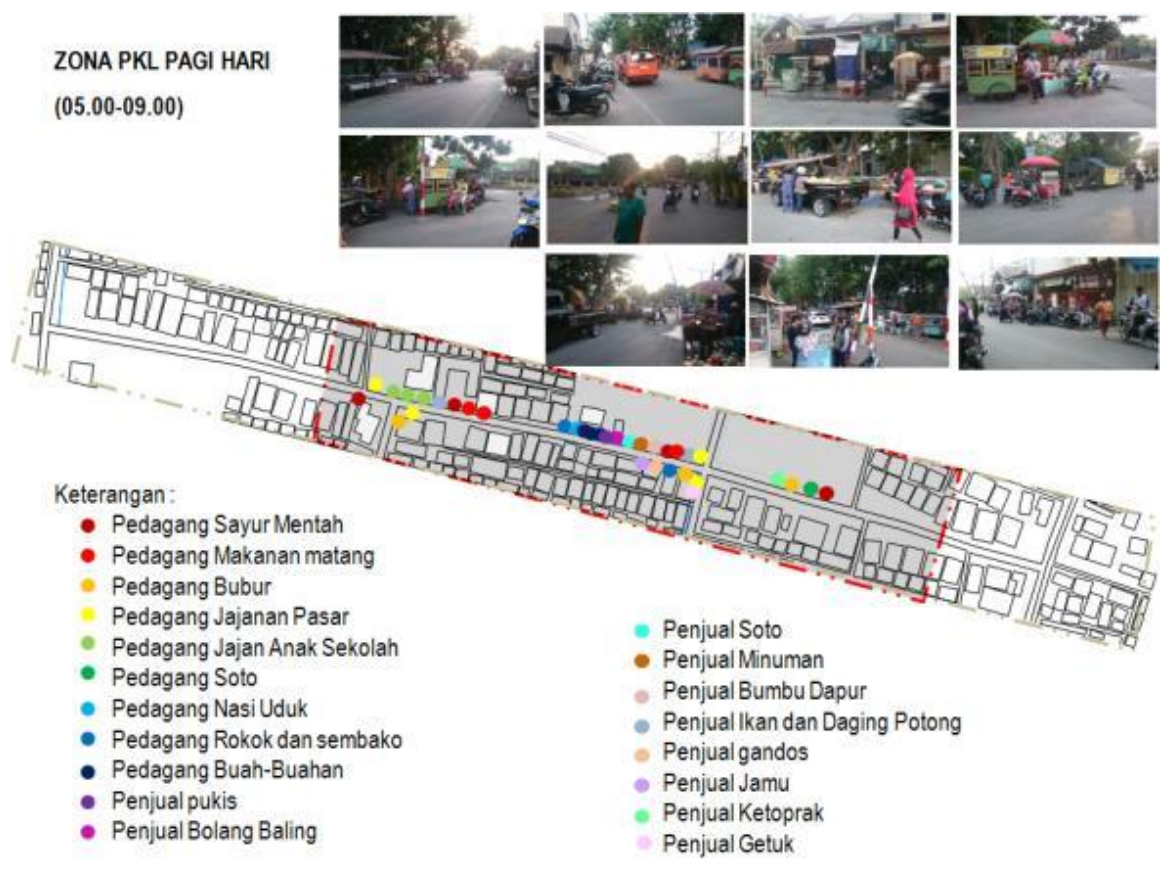

Gambar 2. Place centered mapping pada pagi hari.



Gambar 3. Person centered mapping pada pagi hari.

Jumlah PKL pada pagi hari adalah 33 pedagang (Gambar 3) dengan jenis dagangan yang paling diminati adalah makanan siap saji. Karena pembeli yang melalui jalan dapat langsung membeli makanan dengan cepat. Sarana fisik yang digunakan mudah dibongkar, seperti gerobak, meja, mobil dan motor karena waktu berjualan yang sebentar (lihat Tabel 1). 
Tabel 1. Jenis dagangan, jumlah pkl, sarana fisik pada pagi hari.

\begin{tabular}{|c|c|c|c|c|}
\hline No & Jenis Dagangan & & Jumlah PKL & Sarana Fisik \\
\hline \multirow[t]{4}{*}{1} & Bahan Mentah & 4 & PKL Sayur & Mobil, gelaran, gerobak \\
\hline & & 3 & PKL Buah & Gelaran \\
\hline & & 2 & PKL Daging & Meja \\
\hline & & 1 & Bumbu Dapur & Gerobak \\
\hline \multirow[t]{13}{*}{2} & Makanan Siap & 3 & PKL Makanan Matang & Gerobak \& meja \\
\hline & Konsumsi & 2 & PKL Bubur & Gerobak \\
\hline & & 4 & PKL Jajan Pasar & Gerobak \\
\hline & & 3 & PKL Jajan SD & Motor \\
\hline & & 2 & PKL Soto & Gerobak \\
\hline & & 1 & PKL Nasi Uduk & Gerobak \\
\hline & & 1 & PKL Pukis & Meja \\
\hline & & 1 & PKL Bolangbaling & Gerobak \\
\hline & & 1 & PKL Minuman & Gerobak \\
\hline & & 1 & PKL Gandos & Gerobak \\
\hline & & 1 & PKL Jamu & Sepeda \\
\hline & & 1 & PKL Ketoprak & Gerobak \\
\hline & & 1 & PKL Getuk & Pikulan \\
\hline 3 & Non Makanan & 1 & PKL Rokok & Meja \\
\hline \multirow[t]{2}{*}{4} & Jasa & & - & - \\
\hline & JUMLAH TOTAL & 33 & PKL PAGI & \\
\hline
\end{tabular}

3.1.2 Siang hari (12.00 - 16.00 WIB). Aktivitas PKL pada siang hari pada pukul $12.00-16.00$ WIB jumlahnya lebih berkurang dari pada pagi hari (lihat Gambar 4).



Gambar 4. Place centered mapping pada siang hari. 


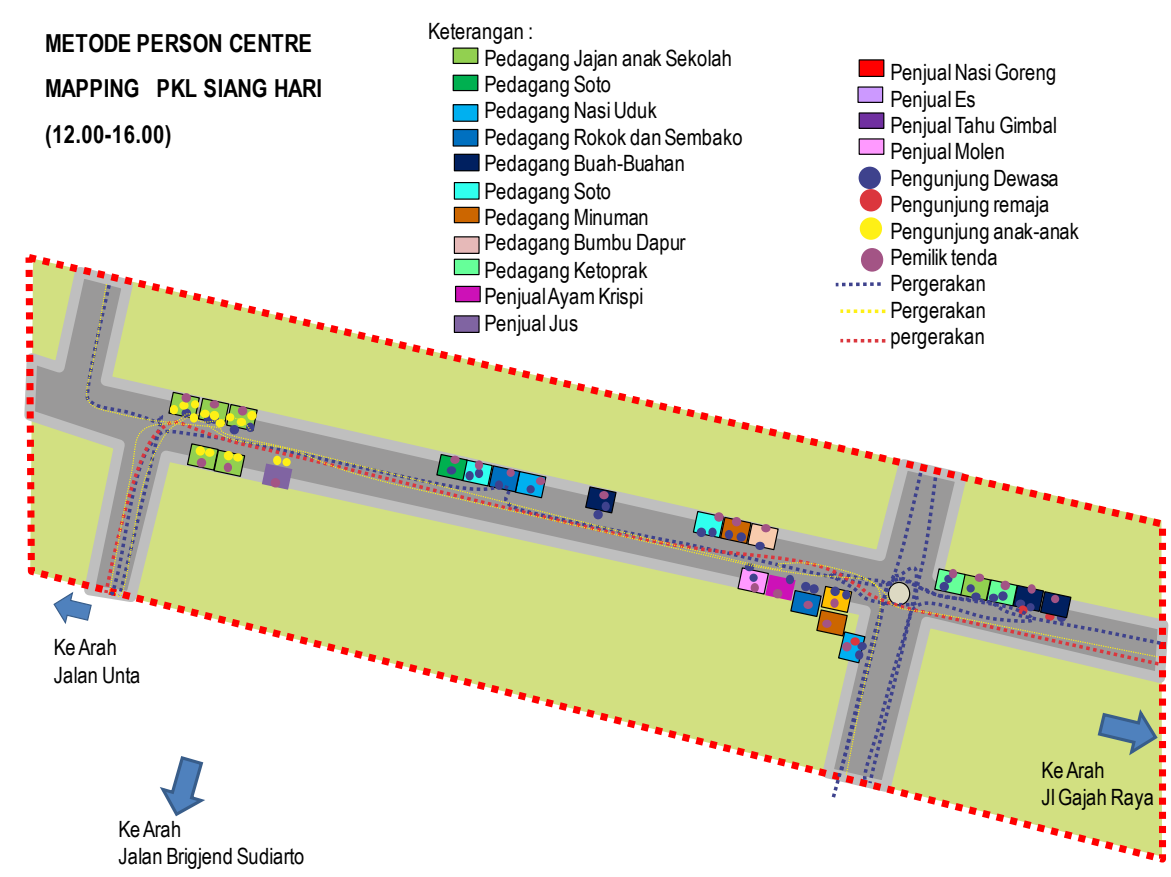

Gambar 5. Person centered mapping pada siang hari.

Pada siang hari pergerakan aktivitas pembeli lebih lenggang sehingga mempengaruhi jumlah pedagang kaki lima yang berada di lokasi (lihat Gambar 5). PKL pada siang hari berjumlah 21 PKL didominasi makanan dan minuman. Selain itu, pedagang tidak menetap tetapi berkeliling di sekitar perumahan dengan gerobak dorong dan kendaran bermotor untuk memudahkan pergerakan (lihat Tabel 2).

Tabel 2. Jenis dagangan, jumlah PKL, sarana fisik pada siang hari.

\begin{tabular}{|c|c|c|c|c|}
\hline No & Jenis Dagangan & & Jumlah PKL & Sarana Fisik \\
\hline \multirow{2}{*}{1} & Bahan Mentah & 2 & PKL Buah & Gelaran \\
\hline & & 1 & Bumbu Dapur & Gerobak \\
\hline \multirow[t]{11}{*}{2} & Makanan Siap & 6 & PKL Jajan SD & Motor \\
\hline & Konsumsi & 2 & PKL Soto & Gerobak \\
\hline & & 1 & PKL Nasi Uduk & Gerobak \\
\hline & & 1 & PKL Minuman & Gerobak \\
\hline & & 1 & PKL Ketoprak & Gerobak \\
\hline & & 1 & PKL Ayam Krispy & Gerobak \\
\hline & & 1 & PKL Jus & Gerobak \\
\hline & & 1 & PKL Nasi Goreng & Gerobak \\
\hline & & 1 & PKL Es & Gerobak \\
\hline & & 1 & PKL Tahu Gimbal & Gerobak \\
\hline & & 1 & PKL Molen & Gerobak \\
\hline 3 & Non Makanan & 1 & PKL Rokok & Meja \\
\hline 4 & Jasa & & - & - \\
\hline & MLAH TOTAL & 21 & PKL SIANG & \\
\hline
\end{tabular}

Received: Februari 06, 2020; Accepted: March 20, 2020; Available online: July 15, 2021 
3.1.3 Malam hari (17.00 - 21.00 WIB). Aktivitas PKL pada malam hari pada pukul 17.0021.00 WIB didominasi oleh makanan dan jasa mainan anak-anak (lihat Gambar 6). Pada malam hari terjadi kemacetan pada perempatan Jalan Badak $\mathrm{V}$ di saat jam pulang kantor (lihat Gambar 7).

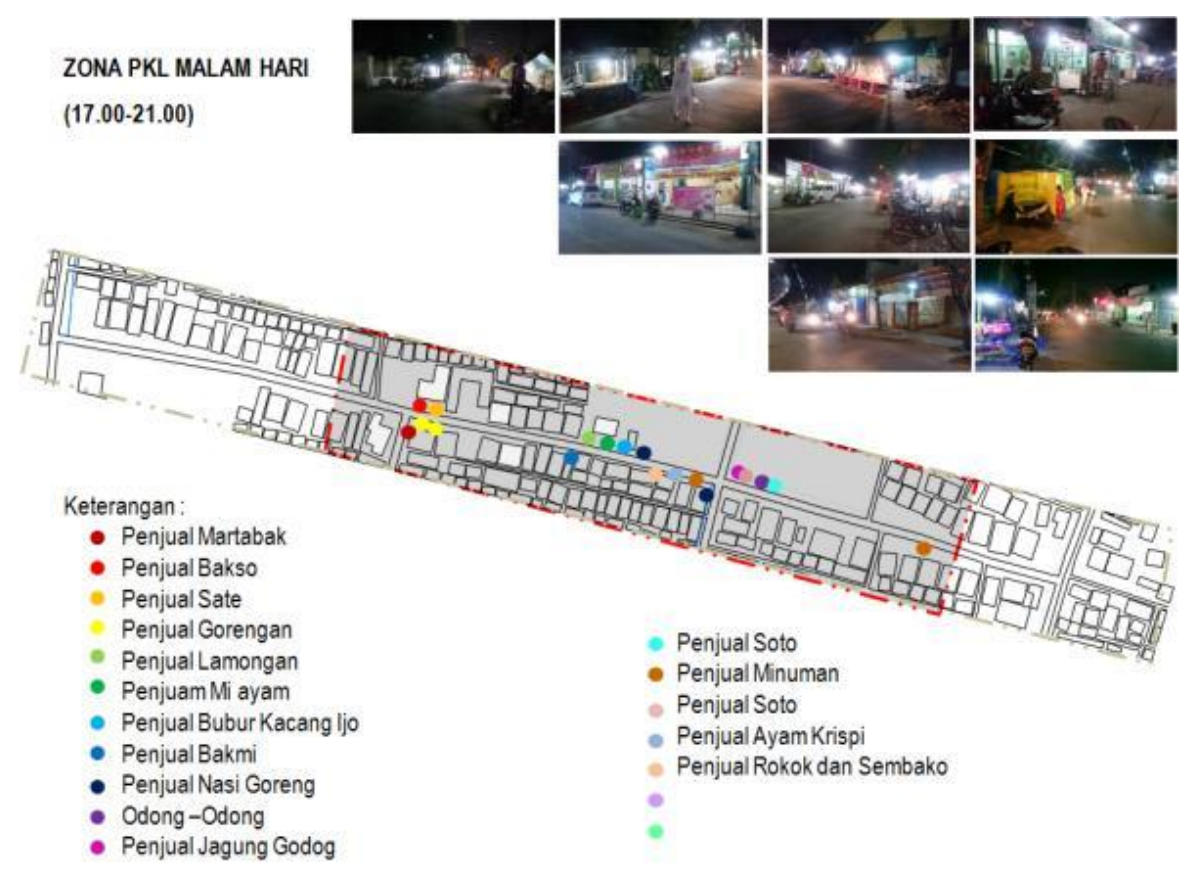

Gambar 6. Place centered mapping pada malam hari.

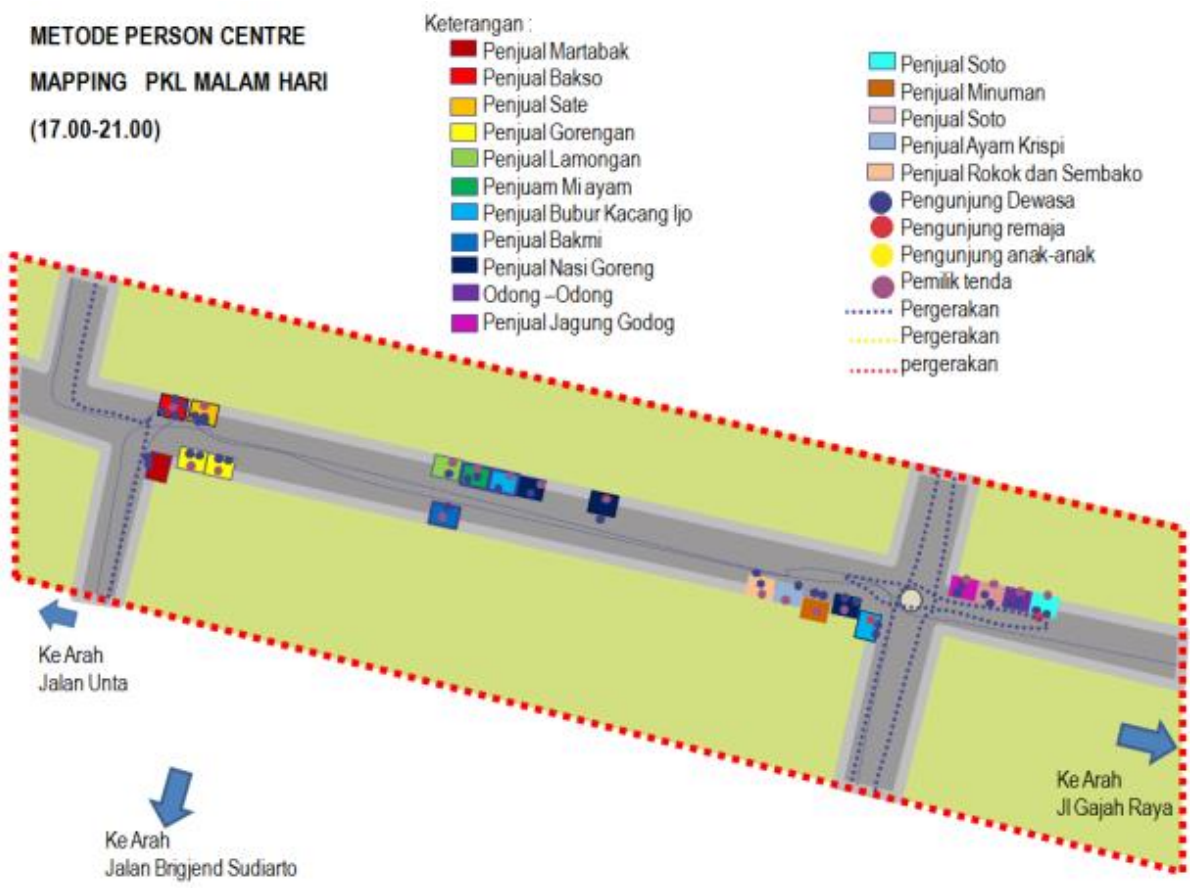

Gambar 7. Person centered mapping pada siang hari. 
Tabel 3. Jenis dagangan, jumlah PKL, sarana fisik pada malam hari.

\begin{tabular}{|c|c|c|c|c|c|}
\hline No & Jenis Dagang & & & Jumlah PKL & Sarana Fisik \\
\hline 1 & Bahan Mentah & & & - & - \\
\hline \multirow{12}{*}{2} & Makanan & Siap & 1 & PKL Martabak & Gerobak \\
\hline & Konsumsi & & 1 & PKL Soto & Tenda \\
\hline & & & 1 & PKL Sate & Tenda \\
\hline & & & 2 & PKL Gorengan & Tenda \\
\hline & & & 1 & PKL Lamongan & Tenda \\
\hline & & & 1 & PKL Miayam & Tenda \\
\hline & & & 1 & PKL Bubur & Gerobak \\
\hline & & & 1 & PKL Bakmi & Tenda \\
\hline & & & 1 & PKL Nasi Goreng & Tenda \\
\hline & & & 1 & PKL Jagung & Gerobak \\
\hline & & & 1 & PKL Minuman & Gerobak \\
\hline & & & 1 & PKL Ayam Krispy & Gerobak \\
\hline 3 & Non Makanan & & & PKL Rokok & Meja \\
\hline \multirow[t]{2}{*}{4} & Jasa & & 2 & Odong Odong & Sepeda \\
\hline & JUMLAH TOTAL & & 15 & PKL MALAM & \\
\hline
\end{tabular}

\subsection{Karakteristik aktivitas $P K L$}

Karakteristik PKL menurut Surya \& Widjajanti [4] dapat ditinjau baik dari sarana fisik, pola penyebaran dan pola pelayanan dalam kecenderungan kegiatan pedagang kaki lima di perkotaan. Berikut merupakan penjabaran karakteristik PKL ditinjau dari sarana fisik, pola penyebaran dan pola pengelola sebagai berikut.

3.2.1 Sarana fisik berdagang PKL. Bentuk sarana fisik dagangan PKL umumnya sesuai dengan jenis dagangan yang dijajakan dan biasanya mudah untuk dipindah-pindah.

3.2.2 Sarana Usaha. Menurut Widjajanti [5], sarana usaha pedagang kaki lima dapat dikelompokan menjadi: (1) kios, (2) warung semi permanen, (3) gerobak/kereta dorong, (4) jongkok/meja, (5) gelaran/alas, dan (6) pikulan/keranjang.

3.2.3 Pola Penyebaran Kegiatan PKL. Pola penyebaran aktivitas PKL menurut McGee \& Yeung [6] dapat dibedakan menjadi: (1) pola penyebaran memanjang (linear concentration), dipengaruhi oleh pola jaringan jalan utama atau jalan penghubungnya yang memiliki aksesibilitas tinggi sehingga berpotensi mendatangkan konsumen, dan (2) pola penyebaran mengelompok (focus aglomeration). Pola penyebaran ini dijumpai pada ruang-ruang terbuka, taman, lapangan, dll. Pola ini dipengaruhi oleh pertimbangan faktor aglomerasi, yaitu keinginan untuk melakukan pemusatan atau pengelompokkan penjaja sejenis dengan sifat dan komoditas sama untuk lebih menarik minat pembeli.

3.2.4 Pola pelayanan kegiatan PKL. Pengelompokan aktivitas perdagangan sektor informal berdasarkan pola pelayanan kegiatannya dikategorikan menurut Widjajanti [5] menjadi: (1) fungsi pelayanan, yang dimiliki oleh aktivitas PKL dalam kehidupan perkotaan secara umum dibagi menjadi fungsi pelayaan perdagangan dan jasa, fungsi pelayanan rekreasi, fungsi 
pelayanan social ekonomi; (2) golongan pengguna jasa, yang dilayani oleh aktivitas PKL pada umumnya adalah golongan menengah ke bawah karena dapat dilihat dari harga yang dapat dijangkau bagi mereka; dan (3) waktu pelayanan, pedagang kaki lima dipengaruhi oleh aktivitas kegiatan di sekitarnya. Jika PKL berjualan di dekat pasar maka saat-saat teramai adalah waktu pagi hari sampai siang dimana kegiatan masyarakat berbelanja cenderung pada pagi hari sampai siang.

3.2.5 Karakteristik aktivitas PKL dalam penelitian. Dalam penelitian ini, karakteristik aktivitas PKL diidentifikasi berdasarkan 5 kategori, yaitu jenis dagangan PKL, sarana dagang PKL, pola penyebaran PKL, sifat layanan PKL, dan waktu dagang PKL. Berikut merupakan penjabaran dari setiap kategori.

- Jenis dagangan PKL

a. Pagi hari jenis dagangan PKL didominasi makanan siap konsumsi dan makanan mentah lebih diminati pembeli karena lebih efisien/cepat dalam memenuhi kebutuhan dapur di pagi hari.

b. Siang hari jenis dagangan PKL didominasi oleh makanan matang dan minuman dingin .

c. Malam hari jenis dagangan PKL didominasi makanan matang yang dapat dimakan di tempat dan jasa mainan anak-anak.

- Sarana dagang PKL

a. Pada pagi hari sarana dagang PKL lebih banyak menggunakan gerobak dorong karena memudahkan pedagang dalam membawa bahan bahan dagangan. Selain itu, mudah dibongkar pasang saat dibawa pulang.

b. Siang hari sarana dagang PKL menggunakan gerobak karena PKL kebanyakan tidak menetap dan memudahkan dalam pergerakan pedagang dalam berkeliling di perumahan.

c. Malam hari sarana dagangan PKL adalah tenda karena pengunjung lebih banyak dan sering makan di tempat sehingga memerlukan sarana yang lebih luas dan nyaman.

- Pola penyebaran PKL

Pola penyebaran PKL pada waktu pagi, siang dan malam adalah pola sebaran linier berderet di tepi jalan karena aksesibilitas lebih mudah dilihat dan dicapai.

- Sifat layanan PKL

Mayoritas PKL di Jalan Badak V adalah menetap karena sudah memiliki pelangggan dan lahan yang disewa untuk berdagang akan sama setiap harinya sesuai dengan waktu beraktivitas.

- Waktu dagang PKL

Waktu dagang PKL di Jalan Badak $\mathrm{V}$ berlangsung pada pagi, siang dan malam hari. Intensitas kegiatan rendah pada siang hari karena PKL lebih sering berkeliling .

\subsection{Karakteristik lokasi PKL}

Karakteristik lokasi yang diminati oleh PKL menurut McGee \& Yeung [6] sebagai berikut.

- Terdapat akumulasi orang yang melakukan kegiatan bersama-sama pada waktu yang relatif sama, sepanjang hari. 
- Berada pada kawasan tertentu yang merupakan pusat kegiatan perekonomian kota dan non-ekonomi kota, tetapi sering dikunjungi dalam jumlah besar.

- Mempunyai kemudahan untuk terjadi hubungan antara pedagang kaki lima dengan calon pembeli, walaupun dilakukan dalam ruang relatif sempit.

- Tidak memerlukan ketersediaan fasilitas dan utilitas pelayanan umum.

Karakteristik lokasi yang diminati oleh PKL adalah pada simpul Jalan Badak V karena akumulasi orang lebih banyak dan mempunyai aksebilitas yang mudah antara pedagang kaki lima dengan calon pembeli, walaupun dilakukan dalam jalan yang ramai dan sempit.

Lokasi penempatan berdagang PKL didasarkan pada sistem sewa yang dikelola oleh RT setempat termasuk keamanan, kebersihan, dan listrik sehingga tidak akan ada saling berebut tempat untuk berjualan.

\section{Kesimpulan}

Dari pembahasan di atas maka dapat disimpulkan bahwa karakteristik aktivitas PKL di Jalan Badak V sebagai berikut.

- Kegiatan yang terjadi di Jalan Badak V mempengaruhi aktivitas PKL dengan jenis dagangan yang dijual akan berbeda antara pagi, siang, dan malam hari.

- Lokasi yang dipilih PKL merupakan lokasi yang strategis, mudah dicapai dan dikelilingi oleh permukiman, perkantoran, pendidikan dan pertokoan sehingga tingkat kunjungan aktivitas masyarakat tinggi.

- Pada lokasi aktivitas PKL di Jalan Badak V tidak sesuai dengan fungsi utama jalan perumahan sebagai sarana transportasi [7] dan sampai saat ini belum diakomodasi ruang khusus PKL walapun sudah banyak kritikan dari pengguna jalan yang terkena kemacetaan saat melewati jalan tersebut.

\section{Referensi}

[1] Badan Standardisasi Nasional. SNI 03-6967-2003 Tentang Persyaratan Umum Sistem Jaringan Dan Geometrik Jalan Perumahan 2003.

[2] Pemerintah Kota Semarang. Peraturan Daerah Kota Semarang No. 11 Tahun 2000 Tentang Pengaturan dan Pembinaan Pedagang Kaki Lima 2000.

[3] Sardjono AB, Sudarwanto B. Pasar di Lingkungan Permukiman. Modul 2011;11:101-6. https://doi.org/10.14710/mdl.11.2.2011.\%p.

[4] Surya OL, Widjajanti R. Kajian Karakteristik Berlokasi Pedagang Kaki Lima di Kawasan Sekitar Fasilitas Kesehatan (Studi Kasus : Rumah Sakit dr . Kariadi Kota Semarang). Universitas Diponegoro, 2006.

[5] Widjajanti R. Karakteristik Aktivitas Pedagang Kaki Lima di Ruang Kota (Studi Kasus: Kawasan Pendidikan Tembalang, Kota Semarang). J Pembang Wil Kota 2012;8:41224. https://doi.org/10.14710/pwk.v8i4.6498.

[6] McGee TG, Yeung YM. Hawkers in Southeast Asian cities : planning for the bazaar economy. Ottawa: International Development Research Centre (IDRC); 1977.

[7] Republik Indonesia. Undang-Undang No. 38 tahun 2004 tentang Jalan 2004. 